\title{
Study on genetic polymorphisms and phenotypic frequency distribution of CYP2C9, CYP2C19 and CYP2D6 in Han Chinese population
}

Li He

Central South University Third Xiangya Hospital

Shaojun Chen

guangxi medical university

Jingao Li

Jiangxi Cancer Hospital

Xiaoxue Xie

Central South University Xiangya School of Medicine

Lihua Huang

Central South University Third Xiangya Hospital

Yun Kuang

Central South University Third Xiangya Hospital

Kangwei Xu

Hunan Normal University

Wanxia Huang

hunan normal nuiversity school of medicine

Yanling Zhao

Central South University Third Xiangya Hospital

Guoping Yang

Central South University Third Xiangya Hospital

Chengxian Guo ( $\square$ gchxyy@163.com)

Central South University https://orcid.org/0000-0002-6332-6716

\section{Research article}

Keywords: Genetic polymorphism, Phenotype, CYP2C9, CYP2C19, CYP2D6

Posted Date: October 18th, 2019

DOI: https://doi.org/10.21203/rs.2.16150/v1 
License: (c) (i) This work is licensed under a Creative Commons Attribution 4.0 International License. Read Full License 


\section{Abstract}

Purpose Genetic mutations and phenotypic changes of CYP2C9, CYP2C19 and CYP2D6 are vital for individual variations in clinical drug responses. Elucidating the mutating frequencies and phenotypic distributions of these genes shall facilitate the implementation of preemptive pharmacogenetic testing. We analyzed the gene polymorphisms and phenotypic frequencies of CYP2C9, CYP2C19 and CYP2D6 in Han Chinese population.

Methods Tests of CYP2C9, CYP2C19 and CYP2D6 were performed in over 3200 (3276-3293) samples in Han Chinese population; furthermore, systematic review was employed for analyzing the mutation frequency and phenotypic distribution of CYP2C9 and CYP2C19 in Han Chinese population.

Results Among 9062 samples, the mutation frequency of CYP2C9 was $11.49 \%$ and the frequency of phenotypic changes $7.1 \%$; in 8222 samples, the mutation frequency of CYP2C19 was $66.07 \%$ and the frequency of phenotypic changes $63.75 \%$; among 3931 samples, the mutation frequency of CYP2D6 was $88.04 \%$ and the frequency of phenotypic changes $3.87 \%$. Among 2690 samples, gene mutations and phenotypic distributions of CYP2C9, CYP2C19 and CYP2D6 were simultaneously examined and it was found that $96.36 \%$ samples became mutated and the frequency of phenotypic changes was $66.51 \%$.

Conclusions In Han Chinese population, the gene mutations and phenotypic changes of CYP2C9, CYP2C19 and CYP2D 6 are all relatively frequent. Prior to dosing, preemptive pharmacogenetic testing of CYP2C9, CYP2C19 and CYP2D6 is recommended.

\section{Introduction}

Genetic polymorphism of metabolic enzymes Cytochrome P450 (abbreviated as CYP450) is one of the important factors causing individual variations in clinical drug responses [1]. As stressed by the U.S. Food and Drug Administration (FDA) and other pharmacogenetic (PGx) guideline-formulating agencies, such as Clinical Pharmacogenetics Implementation Consortium (CPIC), Canadian Pharmacogenomics Network for Drug Safety (CPNDS), Dutch Pharmacogenetics Working Group (DPWG) and French National Network (Réseau) of Pharmacogenetics, most genetic polymorphisms which influences drug responses are related with P450 metabolic enzymes [2]. And the genetic polymorphisms of CYP2C9, CYP2C19 and CYP2D6 have been most thoroughly examined so far in P450 metabolic enzymes [3]. However, there is still an ongoing debate on guiding drug dosing by detecting these main PGx genes [4]. Even the guideline of CPIC only discussed the issue of transforming PGx genotype into clinical phenotype [5]. There was no recommendation of whether or not conducting preemptive pharmacogenetic testing. Existing confusion of PGx genotype testing was mainly due to a lack of convincing evidences for large-scaled clinical trials for confirming the clinical values of PGx [6]. Recently more and more such trials of PGx are performed. For example, CHANCE study has confirmed that, in patients with mild ischemic stroke or transient ischemic attack (TIA), as compared with aspirin dosing alone, a combined use of aspirin and clopidogrel could only lower the occurring rate of new stroke among patients not carrying CYP2C19 loss-of-function 
allele [7]. As demonstrated by Genetic Informatics Trial (GIFT), among patients undergoing elective hip/knee joint replacement and receiving warfarin therapy during perioperative period, as compared with routine clinical drug dosing, genotype-guided dosing of warfarin could lower the risks of major hemorrhage, venous thrombus/embolism and death [8]. As confirmed by a randomized clinical trial of Syn NL et al, the dosing scheme based upon a formula of pharmacogenetic might reduce the dose of warfarin and better predict its maintenance dose in Asian populations. With the elapsing of time, a growing body of convincing evidences from clinical trials shall reiterate the needs of conducting preemptive pharmacogenetic testing [9]. And many current controversies of pharmacogenetic testing may be settled.

However, in addition to the strong clinical research evidence of preemptive pharmacogenetic testing, we should not ignore the influence of genetic polymorphisms and phenotype frequency distribution on preemptive pharmacogenetic testing. If the frequency of genetic polymorphism is low and a small variation exists in phenotypic frequency, then the cost effectiveness of pharmacogenetic test shall be minimal. Thus implementing pharmacogenetic test is to restrain clinically. Other than providing study evidences, we should also pay attention to the frequencies of these VIP PGx genes and their phenotypes. Thus it is possible to evaluate objectively the value of preemptive pharmacogenetic testing. For such wellestablished P450 enzymes as CYP2C9, CYP2C19 and CYP2D6, examining their polymorphisms and phenotypes may provide more comprehensive rationales of guiding clinical drug dosing with preemptive pharmacogenetic testing in Han Chinese population.

\section{Methods}

\section{Allele frequency Data}

Collaborating with Pharmacogenomics database (PGXC, www.chnpgxc.com), Third Xiangya Hospital of Central South University utilized an Illumina HI SEQ X-10 sequencer for detecting multiple VIP PGX genes, including CYP2C9, CYP2C19 and CYP2D 6 polymorphisms, in Han Chinese population of 3200 (3276-3293) subjects. The study was approved by the ethics committee of the Third Xiangya Hospital of Central South University. Furthermore, the PubMed database was searched for the literature reports of CYP2C9 and CYP2C19 polymorphism frequency in healthy Han Chinese population having a sample size of over 100. Ultimately systematic reviews were conducted for analyzing the distributions of CYP2C9 and CYP2C19. Wildtype frequency $=(1-$ overall mutant frequency $) \times 100 \%$. Due to the complexity of CYP2D6 polymorphism involving variation in copy number, only samples supplied by PGXC were detected for CYP2D6 and no systematic review was performed.

\section{Allele nomenclature and definitions}

Based upon the Human CYP Allele Nomenclature Database (https://www.pharmvar.org/) and PharmGKB database (https://www.pharmgkb.org/), star (*) allele was adopted for naming and functional notes. CYP 
allelic genotypic functions included the increased function, normal function, decreased function and no function. Based upon standardized pharmacogenetic terms from the CPIC, the phenotypes of CYP enzymes were classified as ultrarapid, rapid, normal, intermediate and poor metabolizers [10].

\section{Results}

The genotypes and phenotypes of CYP2C9, CYP2C19 and CYP2D6 were evaluated in Han Chinese population. And their sample sizes were 9062, 8222 and 3931 respectively (Table 1, supplemental materials).

The percentage of wildtype CYP2C9 was approximately $88.51 \%$ in Han Chinese population and that of mutated CYP2C9 genotype approximately $11.49 \%$ (Table 1). And the predominant genotype of functionally mutated CYP2C9 was $* 1 / * 3$ and its mutating frequency stood at approximately $6.50 \%$. For other mutations, the genotypic frequency was all under $1 \%$. The phenotypic distribution of CYP2C9 was as follows normal metabolizer (88.5\%), intermediate metabolizer (6.89\%), poor metabolizer $(0.21 \%)$, probable intermediate metabolizer (1.64\%) and probable poor metabolize $(1.43 \%)$. And the phenotypes of approximately $1.33 \%$ genotype remained indeterminate (Table 2 ).

Wildtype CYP2C19 accounted for approximately 33.93\% in Han Chinese population. And the percentage of mutated CYP2C19 genotype was approximately $66.07 \%$ (Table 1). Common functional mutated CYP2C19 genotypes included *1/*2 (37.95\%), *2/*2 (9.67\%), *1/*3 (5.32\%), *2/*3 (3.8\%), *2/*15 (1.56\%) and $* 1 / * 17(1.78 \%)$. The phenotypic distribution of CYP2C19 was as follows: normal metabolizer (34.7\%), intermediate metabolizer (47.36\%), poor metabolizer (14.61\%), rapid metabolizer (1.78\%) and probable intermediate metabolizer ( $1 \%)$. And the phenotypes of approximately $0.55 \%$ genotype remained indeterminate (Table 2).

Wildtype CYP2D6 accounted for $11.96 \%$ in Han Chinese population and mutated CYP2D6 genotype was approximately $88.04 \%$ (Table 1 ). In Han Chinese population, the predominant genotype of CYP2D6 was $\star 1 / * 10$ and $* 10 / * 10$, mutating frequency $24.57 \%$ and $28.8 \%$. However, activity score (AS) of $* 1 / * 10$ and $* 10 / * 10$ were 1.5 and 1 respectively [11]. Both were of normal metabolizer of CYP2D6. Thus the frequency of phenotypic changes for CYP2D 6 was lower than those for CYP2C9 and CYP2C19. For CYP2D6, the predominant genotype was * $10 / * 60$; intermediate metabolizer $(3.35 \%)$ (Activity fraction $=$ $0.5)$; poor metabolizer $(0.52 \%)(A S=0)($ Table 2$)$.

Among 2690 samples, we simultaneously examined the mutating status and phenotypic distribution of genes CYP2C9, CYP2C19 and CYP2D6. The non-mutated samples of CYP2C9, CYP2C19 and CYP2D6 accounted for $3.64 \% ; 96.36 \%$ samples became mutated, the number of enzymatic mutation was one (36.58\%), two (56.10\%) and three (3.68\%) (Table 1). The distribution of phenotypes was as follows: normal enzymatic activity of CYP2C9/CYP2C19/CYP2D6 (32.93\%); altered enzymatic activity (66.51\%). And the number of altered enzymatic activity was one (59.78\%), two (6.54\%) and three (0.19\%) (Table 2). 


\section{Discussion}

Systemic studies were performed for the genotypic and phenotypic distributions of CYP2C9, CYP2C19 and CYP2D6 in Han Chinese population. Furthermore, we also examined the co-existing patterns of genotypes and phenotypic changes for CYP2C9, CYP2C19 and CYP2D6.

In this study, we conducted systematic review of the frequencies of common CYP2C9 gene polymorphisms. It was discovered that, among Han Chinese population, the major genotype of causing CYP2C9 functional alterations was $* 1 / * 3$ with a mean mutating frequency of $6.50 \%(3.5 \%-9.81 \%)$. The frequency of this genotype was lower in Chinese populations than that in Caucasian (11.33\%), Middle Eastern (14.32\%) and South/Central Asian (16.0\%) counterparts and yet higher that in African (1.79\%) and African American (2.02\%) counterparts. The figure was somewhat closer to that of Americas (5.79\%). As for CYP2C9, the frequencies of intermediate and poor metabolizers were $6.89 \%$ and $0.21 \%$ respectively. Both were lower than those of Caucasian (31.99\%, 4\%), Middle Eastern $(35.52 \%, 5.33 \%)$, South/Central Asian (33.30\%, 4.45\%), African American (23.47\%, 1.84\%), African (23.06\%, 1.77\%) and Americas (19.70\%, 1.23\%) (supplemental materials).

In this study, we systematic review the frequencies of common gene polymorphisms of CYP2C19. It was found that, in Han Chinese population, the predominant allelic genotypes of $* 2$ and $* 3$ induced the functional changes of CYP2C19 and lowered enzymatic activity. In Han Chinese population, the frequencies of intermediate and poor metabolizers of CYP2C19 metabolizing enzyme $(47.36 \%, 14.61 \%)$ were higher than those of Caucasian (26.8\%, 2.5\%), Middle Eastern (26.4\%, 2.4\%), African American (32.3\%, 4.3\%), African (24.1\%, 4.8\%) and Americas (25.9\%, 2.3\%) populations. The figures were closer to those of South/Central Asian (45.6\%, 12.4\%). However, the frequency of CYP2C19 rapid metabolizer $(1.78 \%)$ was lower than that of Caucasian (26.9\%), Middle Eastern (25.9\%), African American (23.6\%), African (13.6\%), Americas (21.8\%) and South/Central Asian (16.4\%) populations (supplemental materials).

Based upon the samples of PGxC, the common polymorphisms of CYP2D6 were detected in Han Chinese population. It was found that * 10 allelic genes had the highest mutation frequency. The frequencies of both $* 1 / * 10(24.57 \%)$ and $* 10 / * 10(28.80 \%)$ were higher than those of Caucasian $(0.75 \%, 0.08 \%)$, Middle Eastern (1.85\%, 0.12\%), African American (1.34\%, 0.017\%), African (0.95\%, 0.44\%), Americas (1.92\%, $0.07 \%)$ and South/Central Asian $(10.47 \%, 3.01 \%)$ populations. Yet both $* 1 / * 10$ and $* 10 / * 10$ were of normal metabolizer. Thus the frequency of CYP2D6 phenotypic changes was relatively low. And the frequencies of CYP2D6 intermediate and poor metabolizers were $3.35 \%$ and $0.52 \%$ respectively. Both were lower than those of Caucasian (7.18\%, 6.07\%), Middle Eastern (5.64\%, 1.20\%), African American (13.21\%, 3.05\%), African (12.56\%, 1.88\%), Americas (4.48\%, 3.66\%) and South/Central Asian (6.31\%, $3.011 .28 \%$ ) populations. In our study, the predominant genotype of inducing altered enzymatic activity of CYP2D 6 was $* 10 / * 60$. The limitation of our study lied in the fact that copy number of CYP2D 6 was not analyzed. Thus the data were still lacking for rapid/ultrarapid metabolizer of CYP2D6 in Han Chinese population (supplemental materials). 
In the mean time, we also analyzed the genotypes and phenotypes of CYP2C9, CYP2C19 and CYP2D6. The overall mutation rate was as high as $96.36 \%$; and the ultimate mutating frequency of inducing altered enzymatic activity was up to $66.51 \%$. It hinted that adjusting drug doses was essential for at least half of Chinese populations using common substrate drugs of CYP2C9, CYP2C19 and CYP2D6.

In Han Chinese population, the genetic mutations and phenotypic changes of CYP2C9, CYP2C19 and CYP2D 6 are all relatively frequent. It is worth noting that the mutations and phenotypic changes of CYP2C19 have surpassed $60 \%$; there is a higher prevalence of triple-gene mutations and phenotypic changes. This study shall facilitate the implementation of preemptive pharmacogenetic testing in Chinese population.

\section{Declarations}

Authors' contributions All authors including LH, SC, JL, XX, LH, YK, YZ, HT, QP, GY and CG have made substantial, direct and intellectual contribution to the work and approved it for publication.

Funding information This work was supported by National Natural Science Foundation of China (81974511), Scientific and Technological Project of Hunan (2019SK2124), the New Xiangya Talent Project of the Third Xiangya Hospital of Central South University (JY201505).

Conflict of interest The authors declare that they have no conflict of interest.

\section{References}

1Zhou Y, Ingelman-Sundberg M, Lauschke VM (2017) Worldwide Distribution of Cytochrome P450 Alleles: A Meta-analysis of Population-scale Sequencing Projects. CLIN PHARMACOL THER 102 (4): 688-700 $10.1002 /$ cpt. $690 * 10.1002 /$ cpt. 690

2Guo C, Xie X, Li J, Huang L, Chen S, Li X, Yi X, Wu Q, Yang G, Zhou H, Liu JP, Chen X (2019) Pharmacogenomics guidelines: Current status and future development. Clin Exp Pharmacol Physiol 46 (8): 689-693 10.1111/1440-1681.13097*10.1111/1440-1681.13097

3D’Attis S, Massari S, Mazzei F, Maio D, Vergallo I, Mauro S, Minelli M, Bozzetti MP (2019) Assessment of CYP2C9, CYP2C19, and CYP2D6 Polymorphisms in Allergic Patients with Chemical Sensitivity. Int Arch Allergy Immunol 179 (3): 173-186 10.1159/000497322*10.1159/000497322

4Moyer AM, Caraballo PJ (2017) The challenges of implementing pharmacogenomic testing in the clinic. Expert Rev Pharmacoecon Outcomes Res 17 (6): 567-577

$10.1080 / 14737167.2017 .1385395 * 10.1080 / 14737167.2017 .1385395$

5Caudle KE, Klein TE, Hoffman JM, Muller DJ, Whirl-Carrillo M, Gong L, McDonagh EM, Sangkuhl K, Thorn CF, Schwab M, Agundez JA, Freimuth RR, Huser V, Lee MT, Iwuchukwu OF, Crews KR, Scott SA, Wadelius M, Swen JJ, Tyndale RF, Stein CM, Roden D, Relling MV, Williams MS, Johnson SG (2014) Incorporation of 
pharmacogenomics into routine clinical practice: the Clinical Pharmacogenetics Implementation Consortium (CPIC) guideline development process. CURR DRUG METAB 15 (2): 209-217

6Denny JC, Van Driest SL, Wei WQ, Roden DM (2018) The Influence of Big (Clinical) Data and Genomics on Precision Medicine and Drug Development. CLIN PHARMACOL THER 103 (3): 409-418 $10.1002 /$ cpt. $951 * 10.1002 /$ cpt.951

7Wang Y, Zhao X, Lin J, Li H, Johnston SC, Lin Y, Pan Y, Liu L, Wang D, Wang C, Meng X, Xu J, Wang Y (2016) Association Between CYP2C19 Loss-of-Function Allele Status and Efficacy of Clopidogrel for Risk Reduction Among Patients With Minor Stroke or Transient Ischemic Attack. JAMA 316 (1): 70-78 10.1001/jama.2016.8662*10.1001/jama.2016.8662

8Gage BF, Bass AR, Lin H, Woller SC, Stevens SM, Al-Hammadi N, Li J, Rodriguez TJ, Miller JP, McMillin GA, Pendleton RC, Jaffer AK, King CR, Whipple BD, Porche-Sorbet R, Napoli L, Merritt K, Thompson AM, Hyun G, Anderson JL, Hollomon W, Barrack RL, Nunley RM, Moskowitz G, Davila-Roman V, Eby CS (2017) Effect of Genotype-Guided Warfarin Dosing on Clinical Events and Anticoagulation Control Among Patients Undergoing Hip or Knee Arthroplasty: The GIFT Randomized Clinical Trial. JAMA 318 (12): 1115-1124 10.1001/jama.2017.11469*10.1001/jama.2017.11469

9Syn NL, Wong AL, Lee SC, Teoh HL, Yip J, Seet RC, Yeo WT, Kristanto W, Bee PC, Poon LM, Marban P, Wu TS, Winther MD, Brunham LR, Soong R, Tai BC, Goh BC (2018) Genotype-guided versus traditional clinical dosing of warfarin in patients of Asian ancestry: a randomized controlled trial. BMC MED 16 (1): 104 10.1186/s12916-018-1093-8*10.1186/s12916-018-1093-8

10Caudle KE, Dunnenberger HM, Freimuth RR, Peterson JF, Burlison JD, Whirl-Carrillo M, Scott SA, Rehm HL, Williams MS, Klein TE, Relling MV, Hoffman JM (2017) Standardizing terms for clinical pharmacogenetic test results: consensus terms from the Clinical Pharmacogenetics Implementation Consortium (CPIC). GENET MED 19 (2): 215-223 10.1038/gim.2016.87*10.1038/gim.2016.87

11 Gaedigk A, Sangkuhl K, Whirl-Carrillo M, Klein T, Leeder JS (2017) Prediction of CYP2D6 phenotype from genotype across world populations. GENET MED 19 (1): 69-76

10.1038/gim.2016.80*10.1038/gim.2016.80

\section{Tables}

Table 1 Frequencies of common CYP2C9, CYP2C19 and CYP2D6 genotypes 


\begin{tabular}{|c|c|c|c|}
\hline Gene & $\begin{array}{l}\text { Sample } \\
\text { size }\end{array}$ & Genotype & $\begin{array}{l}\text { Frequency } \\
(\%)\end{array}$ \\
\hline CYP2C9 & 9062 & $* 1 / * 1$ & 88.51 \\
\hline & & $* 1 / * 3$ & 6.50 \\
\hline & & Other* & 4.99 \\
\hline CYP2C19 & 8227 & Overall mutation & 11.49 \\
\hline CYFLCIS & $0 \angle L Z$ & $\begin{array}{l}* 1 / * 1 \\
* 1 / * 2\end{array}$ & $\begin{array}{l}33.93 \\
37.95\end{array}$ \\
\hline & & $\begin{array}{c}* 1 / * 3 \\
* 1 / * 17\end{array}$ & 5.32 \\
\hline & & $\begin{array}{l}* 1 / * 17 \\
* 2 / * 2\end{array}$ & 9.67 \\
\hline & & $\begin{array}{l}* 2 / * 3 \\
* 2 / * 15\end{array}$ & 3.80 \\
\hline & & Other* & 5.99 \\
\hline & & Overall mutation & 66.07 \\
\hline CYP2D6 & 3931 & $\begin{array}{l}* 1 / * 1 \\
* 1 / * 2\end{array}$ & $\begin{array}{c}11.96 \\
4.76\end{array}$ \\
\hline & & $* 1 / * 10$ & 24.57 \\
\hline & & $* 1 / * 41$ & $\begin{array}{l}2.16 \\
1.3\end{array}$ \\
\hline & & $\begin{array}{l}* 1 / * 2 \\
* 2 / * 10\end{array}$ & 2.59 \\
\hline & & $\begin{array}{l}* 2 / * 10 \\
* 10 / * 10\end{array}$ & 10.99 \\
\hline & & $* 10 / * 14 \mathrm{~B}$ & 1.32 \\
\hline & & $\begin{array}{l}* 10 / * 41 \\
* 10 / * 60\end{array}$ & $\begin{array}{l}3.31 \\
2.16\end{array}$ \\
\hline & & Other* & 6.08 \\
\hline \multirow{6}{*}{ CYP2C9+CYP2C19+CYP2D6 } & \multirow{6}{*}{2690} & $\begin{array}{l}\text { Overall mutation } \\
\text { Wildtvpe }\end{array}$ & $\begin{array}{c}88.04 \\
3.64\end{array}$ \\
\hline & & One enzyme with altered enzymatic & 36.58 \\
\hline & & $\begin{array}{c}\text { activity } \\
\text { Two enzymes with altered }\end{array}$ & 56.10 \\
\hline & & $\begin{array}{l}\text { enzymatic activity } \\
\text { Three enzvmes with altered }\end{array}$ & 368 \\
\hline & & enzymatic activity & \\
\hline & & Overall mutation & 96.36 \\
\hline
\end{tabular}

Other* as clustering of non-common genotypes

Table 2 Distribution frequencies of CYP2C9, CYP2C19 and CYP2D6 phenotypes 


\begin{tabular}{|c|c|c|c|}
\hline Gene & $\begin{array}{c}\text { Sample } \\
\text { size }\end{array}$ & Genotype & $\begin{array}{c}\text { Frequency } \\
(\%)\end{array}$ \\
\hline CYP2C9 & 9062 & $\begin{array}{c}\text { Normal metabolizer } \\
\text { Intermediate metabolizer } \\
\text { Probable intermediate metabolizer } \\
\text { Poor metabolizer } \\
\text { Probable poor metabolizer } \\
\text { Indeterminate }\end{array}$ & $\begin{array}{l}88.5 \\
6.89 \\
1.64 \\
0.21 \\
1.43 \\
1.33\end{array}$ \\
\hline CYP2C19 & 8222 & $\begin{array}{c}\text { Rapid metabolizer } \\
\text { Normal metabolizer } \\
\text { Intermediate metabolizer } \\
\text { Probable intermediate metabolizer } \\
\text { Poor metabolizer } \\
\text { Indeterminate }\end{array}$ & $\begin{array}{l}1.78 \\
34.7 \\
47.36 \\
1 \\
14.61 \\
0.55\end{array}$ \\
\hline CYP2D6 & 3931 & $\begin{array}{l}\text { Normal metabolizer } \\
\text { Intermediate metabolizer } \\
\text { Poor metabolizer } \\
\text { Indeterminate }\end{array}$ & $\begin{array}{l}95.43 \\
3.35 \\
0.52 \\
0.7\end{array}$ \\
\hline \multirow[t]{4}{*}{ CYP2C9+CYP2C19+CYP2D6 } & 2690 & $\begin{array}{l}\text { Normal enzymatic activity } \\
\text { One enzyme with altered enzymatic }\end{array}$ & $\begin{array}{l}32.93 \\
59.78\end{array}$ \\
\hline & & Two enzymes with altered & 6.54 \\
\hline & & Three enzymes with altered & 0.19 \\
\hline & & Altered overall enzymatic activity & 66.51 \\
\hline
\end{tabular}

\section{Supplementary Files}

This is a list of supplementary files associated with this preprint. Click to download.

- supplementalmaterials.xlsx 